\title{
IN VIVO ASSESSMENT OF GENOTOXICITY IN BUCCAL CELLS OF CHILDREN UNDERGOING TOOTH RESTORATION
}

\author{
Lidia Gavić ${ }^{1}$, Kristina Goršeta², Domagoj Glavina², Davor Željezić ${ }^{3}$, Nada Galić ${ }^{4}$, Antonija Tadin ${ }^{1}$ \\ ${ }^{1} S t u d y$ of Dental Medicine, School of Medicine, University of Split, Split, Croatia \\ 2Department of Paediatric and Preventive Dentistry, School of Dental Medicine, University of Zagreb, Zagreb, Croatia \\ ${ }_{3}^{3}$ Mutagenesis Unit, Institute for Medical Research and Occupational Health, Zagreb, Croatia \\ ${ }^{4}$ Department of Endodontics and Restorative Dentistry, School of Dental Medicine, University of Zagreb, Zagreb, Croatia
}

\section{SUMMARY}

Objectives: Whereas dental materials came in direct or close contact with oral tissue, it is a great concern about the biocompatibility of those materials. This study was performed to evaluate possible DNA damage to buccal cells exposed to dental materials.

Methods: This prospective, longitudinal clinical study was conducted over a three months period. Class II restorations were placed in 60 young patients with no previous filling using one of three tested dental materials (two glass ionomers; Ketac Molar and lonofil Molar and one compomer material; Twinky Star). DNA damage was analysed by micronucleus assays, in buccal exfoliated epithelial cells.

Results: In patients treated with Ketac Molar, a significant frequency of micronuclei $(p=0.027)$ and binucleated cells in samples taken 30 days following restoration ( $p=0.029)$ was confirmed. In patients treated with Twinky Star, a statistically significant increase in the number of binucleated cells in samples taken after 7 and 30 days following restoration ( $p=0.001$ and $p<0.001$, respectively) was observed. In all samples collected 90 days after treatment, there was no statistical difference in the number of any cell changes.

Conclusion: In this study long-term biocompatibility of tested materials was confirmed. Glass ionomers and compomers are widely used materials in paediatric dentistry, and this study has proved their safety for usage in children.

Key words: restorative dentistry, dental materials, genotoxicity test, DNA damage, glass ionomer cements, compomers

Address for correspondence: L. Gavić, Study of Dental Medicine, School of Medicine, University of Split, Soltanska 2, 21000 Split, Croatia. E-mail: Igavic@mefst.hr

https://doi.org/10.21101/cejph.a5216

\section{INTRODUCTION}

Many different types of dental materials are used to replace destroyed dental tissue. All of them came in direct or close contact with oral tissue. Therefore, it is a great concern about the biocompatibility of those materials, and it is of crucial importance that they are harmless moreover for surrounding oral tissue as well as for an organism in general. Thanks to their exclusive properties, glass ionomers (GIC) and resin materials, compomers and composites are the most commonly used dental materials especially for children, and they are recommended materials for the restorations of primary teeth (1). Namely, glass ionomers chemically bond with dental structures, have a chemically set reaction, containing fluoride, and also allows some moisture in the field of operation. Compomers introduced 20 years after glass ionomers are polyacid modified resin composites, and they combine aesthetic and mechanical properties from resin composites, adhesion properties and the fluoride release of GICs. According to Nicholson, compomers are promising materials for the deciduous teeth treatment (2). Twinky StarTM, light-cured compomer, used in this study is a compomer available in a wide range of colours and with glitter incorporated in it, invented especially for children. According to
Fishman et al. (3), choosing the colour for restorative filling by itself increases children's interest, willingness and cooperation but also decreases the anxiety and fear in the treatment process.

The micronucleus (MN) test was introduced at the end of 19th century by Howell and Jolly, and since then it became the most widely and the most reliable assay to evaluate the cytogenetic damage (4). Micronucleus assay can be done in exfoliated epithelial cells but also in human erythrocytes and lymphocytes (5). The epithelial cells are highly proliferative, and more than $90 \%$ of cancers arise in epithelial tissues, and these cells can be easily collected from the mouth without causing discomfort to patients. The procedure is feasible, cheap, and accurate; final results can be obtained in a short time period, so it is an efficient and widely used method for detection of genetic damage. The cells of oral epithelium are renewed regularly, where the new cells produced by mitosis in the basal layer migrate to the surface to replace rejected ones.

The oral cavity is the initial part of the digestive and respiratory tract. Buccal cells are the first barrier for the inhalation or ingestion route and can metabolize proximate carcinogens to reactive products (6). Oral epithelial cells represent the desired target cells for the early detection of genotoxic changes caused 
by carcinogenic agents that enter the body by inhalation and ingestion, especially those which are used for therapeutic purposes within the oral cavity (5). The presence of micronuclei indicates irreversible genomic instability. It was accepted that the presence of MN in buccal epithelial cells may predict the potential risk of both precancerous and cancerous lesions in digestive or respiratory system (7).

During the cell division, in the stem cells of the basal layer, the genetic damage, breakage or loss of chromosomes can be manifested itself in the form of micronuclei. Also, mentioned changes could manifest as the cells with condensed chromatin, fragmented nucleus (karyorrhexis), pyknosis of the nucleus which is indicative of apoptosis, or they could completely lose its nuclear material (karyolysis) which is indicative of necrosis $(8,9)$.

The aim of this study was to determine in vivo biocompatibility of compomers and glass ionomers in buccal cells by micronucleus test. To the best of our knowledge, this is the first prospective, longitudinal clinical study conducted over a three months period assessing the genotoxicity effects of different widely used glass ionomers and compomers directly in young patients with no previous filling.

\section{MATERIALS AND METHODS}

\section{Subjects}

The study was carried out at the Department of Paediatric and Preventive Dentistry, School of Dental Medicine, University of Zagreb, and approved by the University's Ethical Committee which also confirmed that the study was in full accordance with ethical principles including the World Medical Association Declaration of Helsinki. All participants and their parents/guardians were acquainted with the purpose of the study and asked to sign an informed consent form.

The study comprised 60 patients, 22 boys and 38 girls, aged $6-14$ (mean age $8.67 \pm 2.15$ years). The sample was selected by examining subjects in need of one tooth decay treatment who visited the Dental Clinic for Paediatric and Preventive Dentistry at the School of Dental Medicine of the University of Zagreb. The inclusion criteria for this study were good general health (absence of acute and chronic diseases) without taking any medication, no previous restorations in the oral cavity and no orthodontic appliance.

The subjects were randomly assigned into three numerically equal groups (20 each), according to the material that was used for the restorative procedure. In the first group, the restorations were done using GIC material Ketac Molar (3M Espe, Seefeld, Germany), while in the second group GIC material Ionofil Molar (Voco, Cuxhaven, Germany) was used. In the third group, the restorations were done with the compomer type of material Twinky Star (Voco, Cuxhaven, Germany). The composition of the materials, as provided by the manufacturers, is presented in Table 1. The Class II preparations were incrementally filled with dental materials, according to the manufacturer's instructions.

Each patient filled out a questionnaire answering questions regarding demographic factors (age, gender), lifestyle factors, personal factors (health status, use of medication, X-ray exposure), and dietary aspects.

\section{Sample Collection}

Samples of epithelial cells were collected from each participant using the swab technique; immediately before (control), and 7, 30 and 90 days following the restoration of the tooth. One hour before sampling, the participants were asked to refrain from eating. Since subjects were kids, it was implied that they did not smoke or drink alcohol prior to sampling. After rinsing the oral cavity with tepid water, a buccal swab was taken by gently brushing the gingival area along the glass-ionomer or compomer restoration with an interdental brush and applied to encoded microscopic slides pre-warmed at $37^{\circ} \mathrm{C}$.

\section{Micronucleus Assay in Buccal Epithelial Cells}

After dropping the cells were allowed to air-dry and then fixed in methanol $(80 \% \mathrm{v} / \mathrm{v})$ at $4{ }^{\circ} \mathrm{C}$ for $20 \mathrm{~min}$. Staining was carried out with $5 \%$ Giemsa solution for a period of 10 minutes. Afterward, the slides were rinsed with distilled water and airdried. The analysis was done under a light microscope with a $400 \times$ magnification, and each micronucleus and other nuclear anomalies were additionally verified under $1,000 \times$ magnification Two replicate slides were prepared for each subject, and 1,000 epithelium cells per preparation were scored for each sampling time. Frequencies of nuclear abnormalities other than micronuclei, such as binucleated cells, karyorrhexis, karyolysis, nuclear buds, and "broken eggs" were also evaluated and classified according to Tolbert et al. (8). In order for a micronucleus to be counted as such, it has to meet following conditions: it must consist of nuclear material; completely separated from the parent nucleus; less than $1 / 3$ of the diameter of associated nuclei; smooth, oval or round shaped; on the same plane of focus; and it must be of

Table 1. List of materials investigated in the study

\begin{tabular}{|l|l|l|l|}
\hline & Manufacturer & Lot & Chemical composition \\
\hline Ketac Molar Quick Aplicap & 3M ESPE, Seefeld, Germany & $\# 493820$ & $\begin{array}{l}\text { Al-Ca-La fluorosilicate glass, ZnO } \\
5 \% \text { copolymer acid (acrylic and maleic acid), polyacrylic enoic acid, } \\
\text { tartaric acid, water }\end{array}$ \\
\hline $\begin{array}{l}\text { VOCO lonofil Molar } \\
\text { AC Quick }\end{array}$ & VOCO, Cuxahaven, Germany & $\# 1232230$ & $\begin{array}{l}\text { Aluminofluorosilicate glass and pigments, pure polyacrylic acid, } \\
\text { (+)-tartaric acid, water }\end{array}$ \\
\hline Twinky Star & VOCO, Cuxahaven, Germany & $\# 0919531$ & $\begin{array}{l}\text { Ba-Al- Str-fluorosilicate glass, Silicon dioxide, BisGMA, UDMA, } \\
\text { TEGDMA, carboxylic acid modified methacrylate, camphorquinone, } \\
\text { BHT }\end{array}$ \\
\hline
\end{tabular}


the same colour, texture and refraction as the main nucleus. Cells with two nuclei were considered binucleate. Nuclear anomalies, such as karyorrhexis (nuclear disintegration), karyolysis (dissolution of the nucleus), nuclear buds (precursors of micronuclei) and nucleoplasmic bridges (nuclei that appear cinched) were recorded separately $(8,10)$.

\section{Statistical Analysis}

For statistical evaluation Statistica 7.0 (Dell Software, California, USA) software package was employed. Descriptive statistical analysis was used to determine the basic statistical parameters (mean, standard error, standard deviation, and relative standard deviation, median and minimum and maximum values). The data were subjected to an analysis of variance (ANOVA) using a general linear model procedure of Statistica 7.0 software package. The difference among the tested groups was assessed by analysis of variance and Tukey HSD post hoc test. Multiple regression analysis, General Regression Model (GRM) from linear/nonlinear modelling method and canonical correlation analysis were used for the assessment of the predictor variables influence (age, gender, state of health and use of medication, X-ray exposure, and dietary habits) on dependent variables (number of micronucleated and binucleated cells, cells with nucleoplasmic bridges, nuclear buds, pyknosis, condensed chromatin and karyorrhexis). The results of GRM were expressed in the form of Pareto charts of t values. The Pareto chart represents a series of bars whose heights reflect the impact of each predicted variable on the dependent variable. The bars are arranged in descending order of height from up to down. So, the categories represented by the tallest bar have the highest significance on the dependent variable. Statistical significance was set at $p<0.05$, which is marked with the vertical line in each graph.

\section{RESULTS}

Basic statistical parameters used to gain results for the micronucleus assay in buccal cells before and following the placement of glass ionomer cement (Ketac Molar or Ionofil Molar) and compomer (Twinky Star) are presented in Figures 1 and 2.

Analysis of variance confirmed a statistically significant difference between the tested groups, which were subdivided according to exposure time and type of material used and tested for following parameters: the number of micronucleated and binucleated cells, cells with nucleoplasmic bridges, nuclear buds, pyknosis, condensed chromatin, and karyorrhexis (Figures 3 and 4).

In patients treated with Twinky Star, ANOVA and Tukey HSD post hoc test did not confirm a statistically significant difference in the frequency of micronuclei. The highest frequency was after 7 days following restoration, but it was not statistically significant $(p=0.092)$ compared to the day 0 . Also, there was no statistical difference for the frequency of nucleoplasmic bridges, nuclear buds, pyknosis, condensed chromatin, and karyorrhexis. As opposed to that, the frequency of karyolysis was statistically significant - higher in samples taken 30 days following restoration $(p<0.001)$ compared to the day 0 but also compared to the day 7 and $90(\mathrm{p}=0.020)$. Concerning the frequency of the number of binucleated cells, a statistically significant increase in samples taken after 7 and 30 days following restoration $(\mathrm{p}=0.001$ and $\mathrm{p}<0.001$, respectively) was observed. As opposed to that in samples taken after 90 days there was no statistical difference $(p=0.162)$.

In patients treated with Ketac Molar statistically significant frequency changes in the number of binucleated cells, cells with nucleoplasmic bridges, nuclear buds, pyknosis, condensed chromatin, and karyorrhexis were not observed. As opposite to that ANOVA and Tukey HSD post hoc test confirmed a statistically significant difference in the frequency of micronuclei in samples taken 30 days following the restoration $(p=0.027)$. In the samples collected 7 and 90 days following the restoration, there were no statistical differences.

Lastly, in patients treated with Ionofil Molar, according to ANOVA and Tukey HSD post hoc test statistically significant frequency changes in the number of micronucleated cells, cells with nucleoplasmic bridges, nuclear buds, pyknosis, condensed chromatin, and karyorrhexis were not observed. The only significant difference was observed in the number of binucleated cells in samples taken 30 days following the restoration $(p=0.029)$.

There was no statistically significant difference between the three tested materials during the same time of exposure for these parameters, except for the number of binucleated cells in the samples taken 7 days following the restoration with Twinky Star and Ketac Molar $(\mathrm{p}=0.010)$.

A general model of regression was employed to evaluate the influence of the subjects' general characteristics (age, gender, state of health and use of medication, X-ray exposure, and dietary habits) on the parameters of the number of binuclear and micronuclei cells, number of nuclear buds and nucleoplasmic bridges, karyolysis and karyorrhexis. None of the tested factors was found to significantly influence the condensation of the chromatin and the number of nuclear buds (Figure 3). Time of exposure and type of material had a significant effect on the occurrence of micronuclei cells $(\beta=0.296, p=0.018$ and $\beta=0.202, p=0.024$, respectively) while only the time of exposure was found to impact the karyolysis $(\beta=0.255, \mathrm{p}=0.005)$ positively but also pyknosis $(\beta=0.248, p=0.007)$. Consumption of canned meat, type of material, time of exposure, and age significantly impact the occurrence of binuclear cells $(\beta=0.287, p=0.009 ; \beta=0.281, p=0.017$; $\beta=0.194, p=0.022 ; \beta=-0.328, p=0.022$, respectively). Among the possible confounding variables, only the gender displayed a connection to the number of nucleoplasmic bridges $(\beta=-0.301$, $\mathrm{p}=0.039$ ). The greatest number of tested factors had a significant effect on the occurrence of karyorrhexis: exposure to RTG, tea intake, gender, time of exposure, and vegetable intake $(\beta=0.331$, $p=0.007 ; \beta=-0.275, p=0.022 ; \beta=-0.292, p=0.033 ; \beta=0.170$, $p=0.045$; and $\beta=0.276, p=0.046$, respectively) (Figure 4).

\section{DISCUSSION}

The aim of this study was to evaluate the potential genotoxic effect of glass ionomer cements and compomer material from buccal cells in the proximity of dental restoration. The genotoxicity effects were assessed by micronucleus assay in buccal exfoliated epithelial cells because oral epithelial cells represent a preferred target site for early genotoxic events (11). All patients in this study were children with one of the dental materials listed before what allows time for cells to undergo mitosis. 


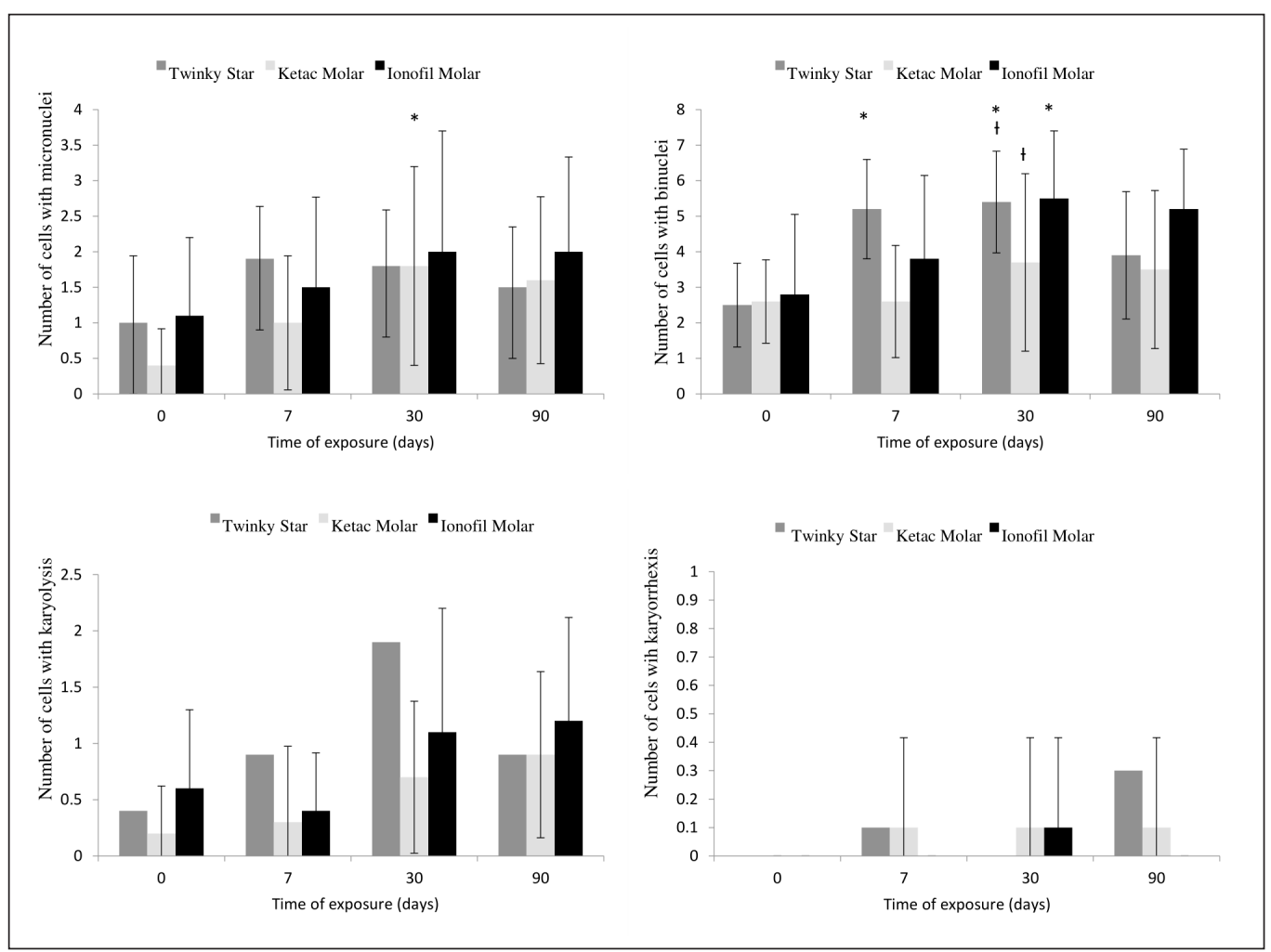

Fig. 1. The frequency of cells with micronuclei, binuclear cells, karyolysis and karyorrhexis in 1,000 buccal epithelial cells of patients ( $n=20 /$ material) treated with glass-ionomers or compomer materials for each time-point of measurement.

Mean values are expressed as columns, error bars represent standard deviations.

*Statistically significant values $(p<0.05)$ in comparison to the values prior treatment $(0$ days).

†Statistically significant values $(p<0.05)$ between materials in the same time-point of measurement.

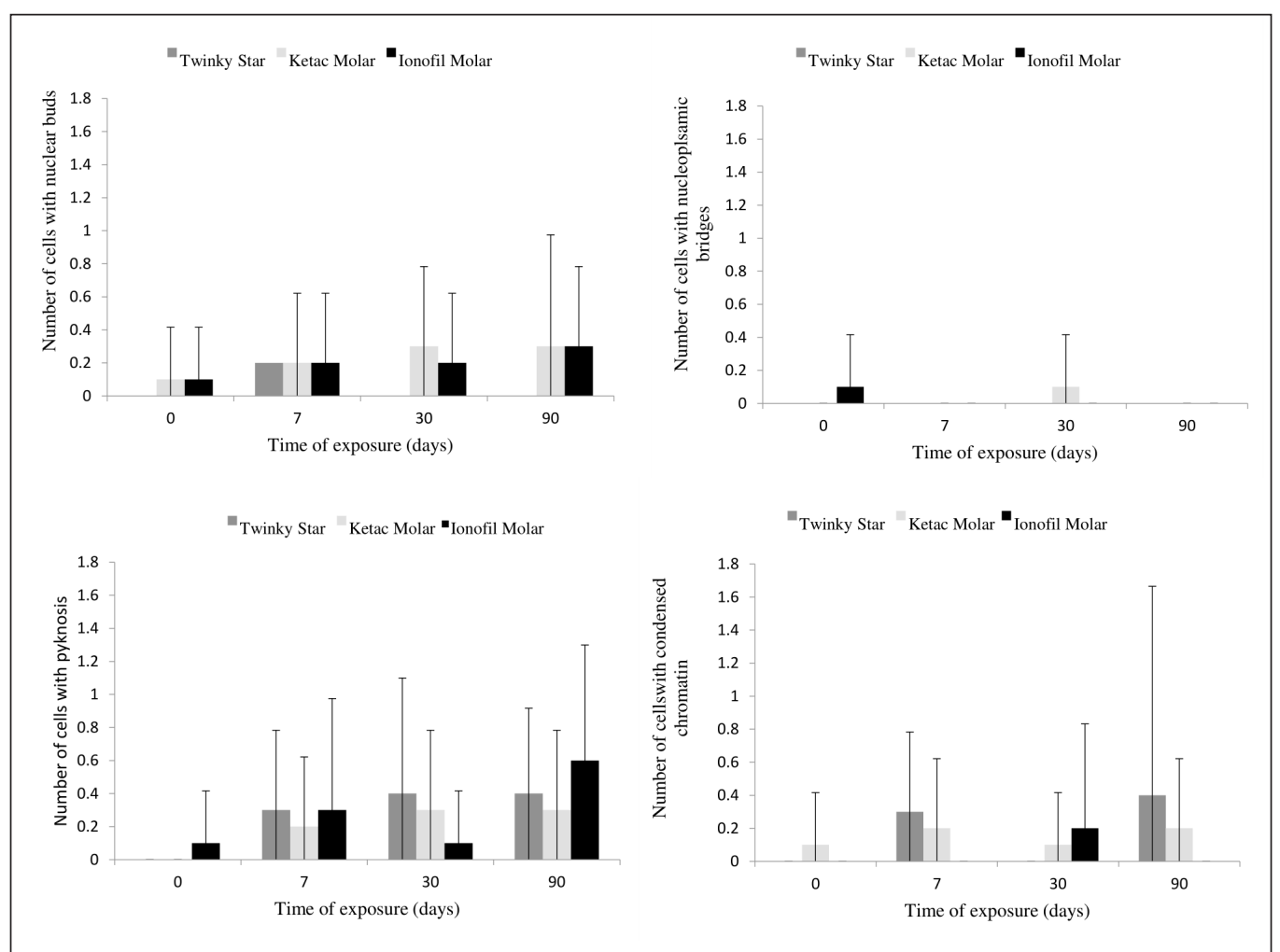

Fig. 2. The frequency of cells with nuclear buds, nucleoplasmic bridges, pyknotic cells and cells with condensed chromatin in 1,000 buccal epithelial cells of patients $(n=20 /$ material) treated with glass-ionomers or compomer materials for each time-point of measurement.

Mean values are expressed as columns, error bars represent standard deviations. 
Since it has been for the first time used on the buccal mucosa, micronucleus assay is widely used, and such an in vivo examination permits the elucidation of the agents directly in a target tissue, buccal epithelium (12). Micronucleus assay is based on the frequency of small nucleus resembling structures in the cytoplasm (10). Micronuclei are fragments or whole chromosomes which did not reach spindle poles and remanded as a microscopically visible round to oval cytoplasmic chromatin mass next to the nucleus $(11,13)$. The presence of a micronucleus in the cell indicates irreparable genomic damage, and the basal layer of oral epithelium contains the stem cells that may express genetic damage (chromosome breakage or loss) as MN during nuclear division $(10,14)$. Whereas the formation of micronuclei presents a morphological manifestation of genomic damage, cells must undergo at least one cell division cycle (15). The optimal timing between 7 and 21 days after exposure is needed because peak expression may vary depending on the effects of particular DNA damage or chromosomal exposure on the basal cell turnover rate. In this study, a significant increase in the number of micronucleated cells was only confirmed in subjects who were treated with Ketac Molar, and it was only observed 30 days after treatment. After 90 days the number of micronuclei cells has been decreased which confirmed long-term biocompatibility of material. This significant initial increase in the number of micronuclei could be explained by the fact that dental materials release small doses of potentially toxic substances in their environment that is especially noted in the first 30 days (16). Galic et al. in their in vitro study also reported a slight increase in the micronucleus frequency in lymphocytes treated with eluates of Ketac Molar (17). They assumed it was indicating the persistence of leached active components, presumably $\mathrm{ZnO}$ that was suspected to be clastogenic. Glass ionomers also contain metal components, such as aluminum, iron and calcium, so the cytotoxic effects of GICs, according to Santos et al., may be attributed to those components (18). Leaching of these ions is proven, and the most attention regarding biocompatibility was dedicated to the extended release of aluminum because aluminum is known to have nuclear effects and it is also responsible for increased chromosomal aberration (19).

In addition to metals, glass ionomers also contain fluoride, which releases into the environment especially at low $\mathrm{pH}$ and thus reduces the acid solubility of hard tissue. The highest amount of fluoride releases initially, in the first few hours till the month after placement, but the fluoride release has been found even after the period of 2 years after placement. Also, the release of fluoride increases after application of fluoride gels. This exclusive property of fluoride release allows the caries protective effect but also enhances the possibility of adverse effects of fluoride. Fluoride exerts various toxic cellular effects, mainly consisting of its interaction with enzymes whether to act as an enzyme inhibitor including phosphatases or stimulate enzyme activity (20). Furthermore, fluoride promotes cell proliferation which under the microscope could also be detected as an increase in the number of binuclear cells. The increase in the number of binuclear cells was observed after 7 and 30 days in specimens after the placement of Twinky Star restoration, and 30 days after the placement of Ionofil Molar restoration concerning initially taken samples, but after 90 days the number of binucleated cells returned to normal. After 30 days it was observed that frequency means of binuclear cells were significantly higher in samples after the Twinky Star restoration in comparison with the Ketac Molar restorations. Our results are consistent with the study of Rezende et al. (21), where an increase in the number of binucleated cells after treatment with dental materials containing monomers was noticed. Namely, the greater increase was observed after treatment with Twinky Star, material which contains monomers. Although necrosis can be partly induced by mechanical damage to oral cells due the swabbing technique used, close contact of material and oral mucosa may cause the oral damage and cell death. In this study, the different morphological changes in cell nuclei: karyolysis, pyknosis, and karyorrhexis, which describe the different morphological manifestation of cell death, were observed. Pyknosis is irreversible condensation of chromatin, and it is followed by karyorrhexis or fragmentation of the nucleus (22). Results from this study indicate no statistically significant effects of treatment with different materials in the number of cells with pyknosis or karyorrhexis.

In the morphological picture of karyolysis, DNA is slowly disappearing, and karyolysis presents the late stage of the cell death process. In our research, the significant increase in karyolysis was observed only after 30 days after treatment with Twinky Star.

As noted earlier, Twinky Star is compomer, the only material in this study which contains, according to the manufacturer, various polymerizable monomers; BIS-GMA, diurethane dimethacrylate, and TEGDMA. Urcan et al. found that the most commonly used monomers show cytotoxic response and that their metabolic radical intermediates have the potential to induce even DNA double strand breaks (23). According to them, the most cytotoxic monomer is BisGMA. The integral part of the molecule BisGMA is Bisphenol A, a molecule which could produce an estrogenic effect (24). Chang et al. in their study tested Twinky Star compomer, and they concluded that it possesses good biological property (25). Namely, the haemolytic test was lower than 5\%, the results of the acute general toxicity test were negative, and samples had no toxicity. Quinlan et al. investigated the potential cytotoxicity of compomer and they concluded that it could be potentially toxic, especially if it is partially cured, and it causes the cell death (26). There was no significant increase in the formation of nucleoplasmic bridges, nuclear buds or the increase of pyknosis or condensed chromatin at any material used in this study in any considered period.

According to Nefic and Handzic, a number of biological, ecological, environmental, demographic, and lifestyle factors can affect micronucleus frequency (27). Namely, numerous biological, environmental and demographic factors can interfere with in vivo researches. Medical procedures (radiation, chemicals), micronutrient deficiency (folic acid), lifestyle factors (alcohol, smoking, drugs, exercise, stress, nutrition) and genetic factors can influence damage to the DNA molecule and to genotoxicity, thus they can interfere with genotoxin toxicity analysis (28). Therefore, a general model of regression has been employed to evaluate their influence on the parameters of DNA damages.

According to the results of multiple regression analysis, the incidence of micronucleated cells significantly depended only on the material used for filling and the time elapsed from filling placement. Our observations are in agreement with those published by Tadin et al., who also failed to detect any significant effect of lifestyle factors on the incidence of micronuclei in the oral mucosa cells (10). Some studies found that increase in micronuclei 


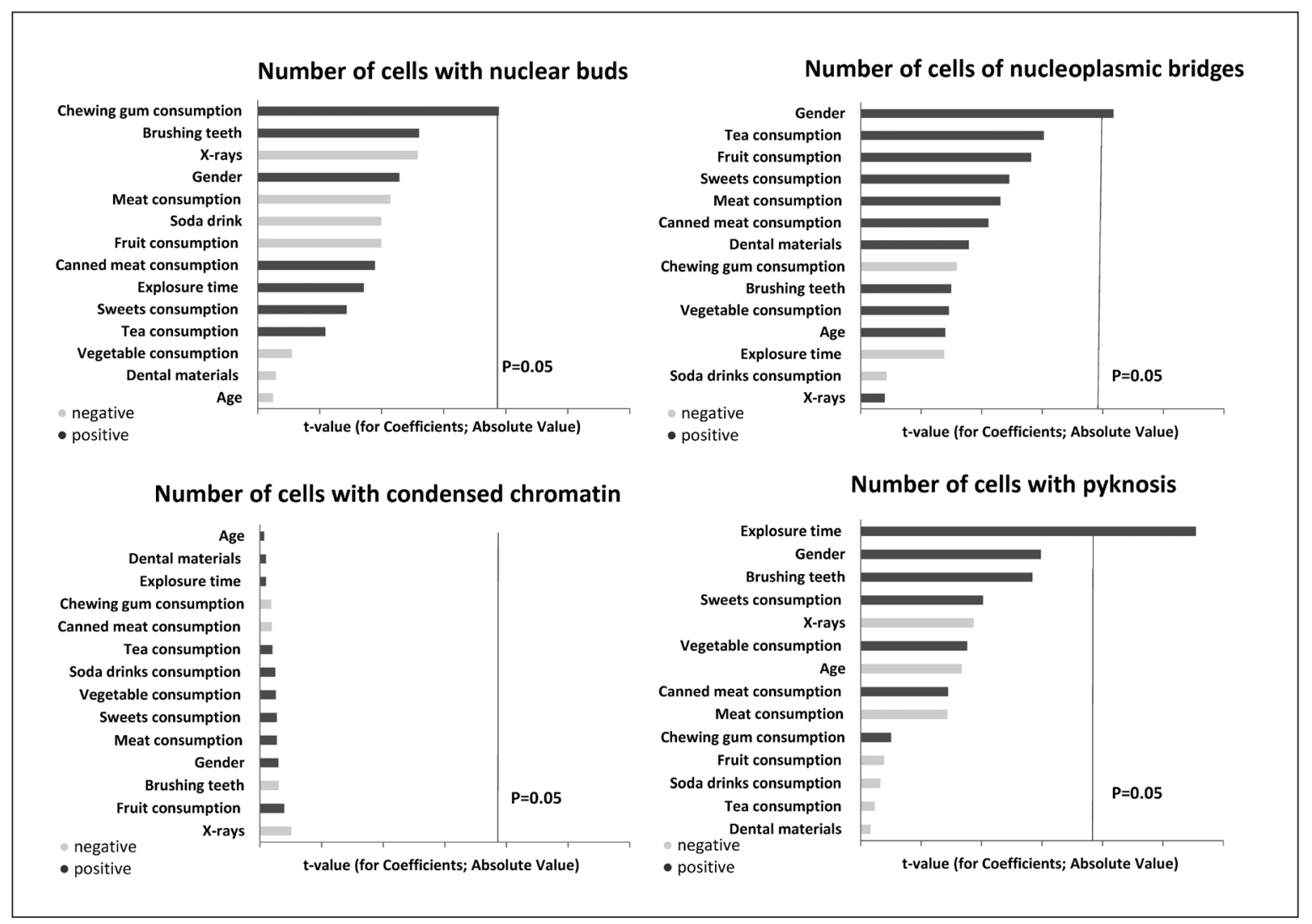

Fig. 3. Multiple regression analysis results. Significant dependence of measured cytogenetic endpoints (cells with nuclear buds, nucleoplasmic bridges, pyknotic cells and cells with condensed chromatin) on gingival cells sampling time (exposure duration), type of dental material used for restoration and demographic and lifestyle factors as possible predictors.

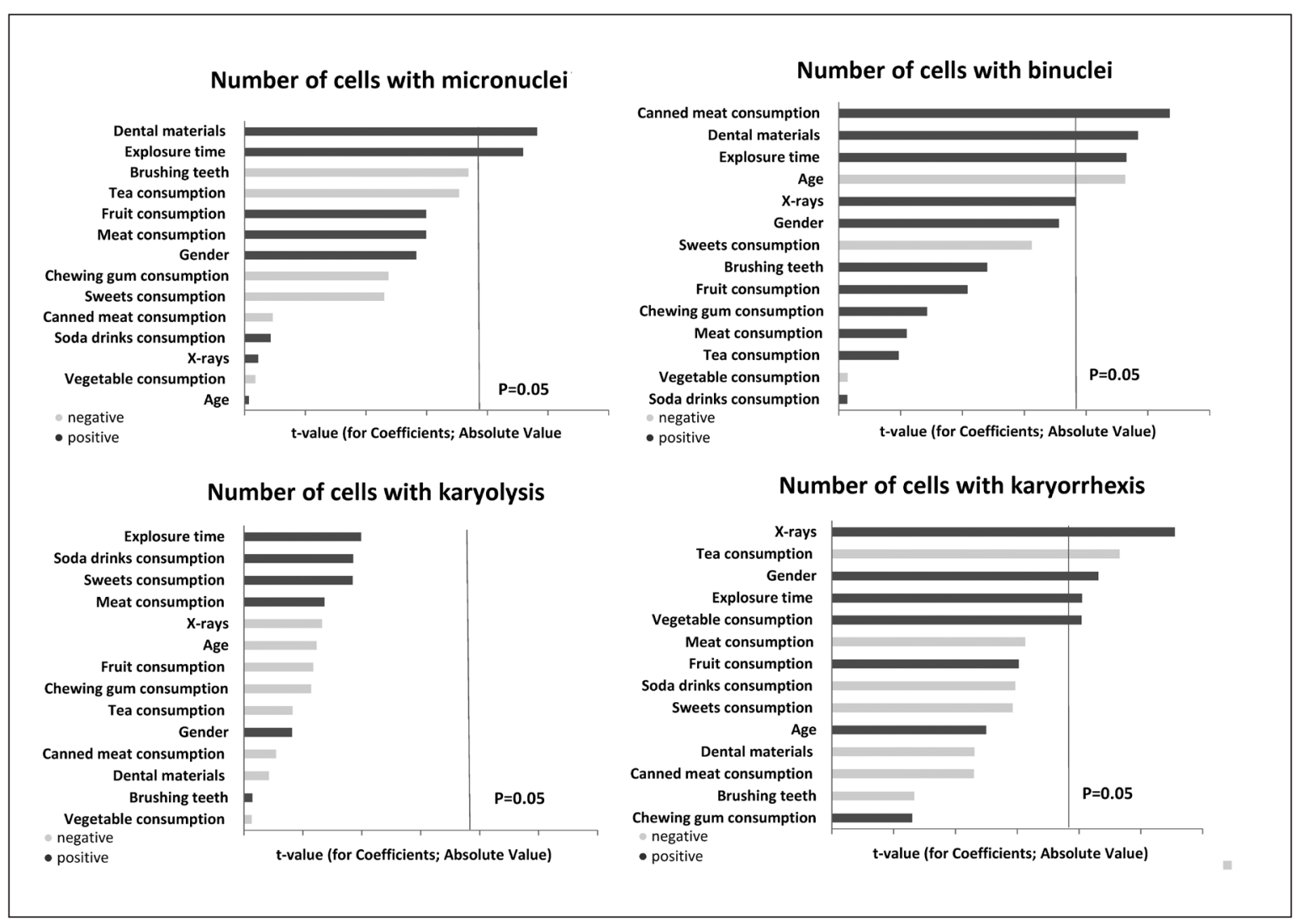

Fig. 4. Multiple regression analysis results. Significant dependence of measured cytogenetic endpoints (cells with micronuclei, binuclear cells, karyolysis and karyorrhexis) on gingival cells sampling time (exposure duration), type of dental material used for restoration and demographic and lifestyle factors as possible predictors. 
is connected with alcohol consumption and smoking (9), but since this study was conducted on children, those factors were excluded. In this study, the number of micronuclei was slightly higher in girls, but the difference was not statistically significant. In some studies higher frequency of micronucleus was observed in women, but this discrepancy usually occurred in younger age and it might be related to the fact that the micronucleus in women commonly contains the inactive X chromosome $(11,29)$. Results in this study are in agreement with those published by Bonassi et al. (30) who reported that effect of gender on the frequency of micronucleus in exfoliated buccal cells is not significant. Ferraz et al. (9) also indicated that the gender did not affect the frequency of micronuclei, but they reported that karyolysis and karyorrhexis were more common among man, contrary to our results, where the karyorrhexis was more often observed among girls than boys. Besides that, the number of binucleated cells significantly depended on the material used for filling and the time elapsed from filling placement but also on the frequency of consuming canned meat, and an inverse correlation with the age of the patient was detected. These diminished rates of binucleated cells could mean slowing proliferative capacity of an organism in general (31). This study has certain limitations. Even the buccal micronucleus assay is minimally invasive, painless and easy access to sample collection; there is technical heterogeneity of the sampling procedure because there is no robotic system that could collect cells uniformly $(5,30)$.

Besides that, this is an in vivo study which cannot be standardized, but it allows an evaluation of effects in their natural setting. Each patient served as the own control to eliminate the individual variations and was regularly monitored over time. Based on our results obtained in this study we can conclude that the observed increase in DNA damage is only temporary and may have no biological significance, which confirmed long-term biocompatibility of tested materials.

\section{CONCLUSION}

Based on results obtained in this study we can conclude that the observed increase in DNA damage is only temporary and may have no biological significance, which confirmed long-term biocompatibility of tested materials. Our study has proved that the mentioned dental materials are safe for future restoration usage especially in paediatric dentistry.

\section{Conflicts of Interests}

None declared

\section{REFERENCES}

1. Lazaridou D, Belli R, Kramer N, Petschelt A, Lohbauer U. Dental materials for primary dentition: are they suitable for occlusal restorations? A two-body wear study. Eur Arch Paediatr Dent. 2015;16(2):165-72.

2. Nicholson JW. Polyacid-modified composite resins ("compomers") and their use in clinical dentistry. Dent Mater. 2007;23(5):615-22.

3. Fishman R, Guelmann M, Bimstein E. Children's selection of posterior restorative materials. J Clin Pediatr Dent. 2006;31(1):1-4.

4. Hayashi M. The micronucleus test-most widely used in vivo genotoxicity test. Genes Environ. 2016;38:18. doi: 10.1186/s41021-016-0044-x.
5. Holland N, Bolognesi C, Kirsch-Volders M, Bonassi S, Zeiger E, Knasmueller $\mathrm{S}$, et al. The micronucleus assay in human buccal cells as a tool for biomonitoring DNA damage: the HUMN project perspective on current status and knowledge gaps. Mutat Res. 2008;659(1-2):93108.

6. Tanaka T, Ishigamori R. Understanding carcinogenesis for fighting oral cancer. J Oncol. 2011;2011:603740. doi: 10.1155/2011/603740.

7. Bloching M, Hofmann A, Lautenschlager C, Berghaus A, Grummt T. Exfoliative cytology of normal buccal mucosa to predict the relative risk of cancer in the upper aerodigestive tract using the $\mathrm{MN}$-assay. Oral Oncol. 2000;36(6):550-5.

8. Tolbert PE, Shy CM, Allen JW. Micronuclei and other nuclear anomalies in buccal smears: methods development. Mutat Res. 1992;271(1):69-77.

9. Ferraz GA, Costa Neto AO, Cerqueira EMM, Meireles JRC. Effects of age on the frequency of micronuclei and degenerative nuclear abnormalities. Rev Bras Geriatr Gerontol. 2016;19(4):627-34.

10. Tadin A, Galic N, Mladinic M, Marovic D, Kovacic I, Zeljezic D. Genotoxicity in gingival cells of patients undergoing tooth restoration with two different dental composite materials. Clin Oral Investig. 2014;18(1):8796.

11. Kashyap B, Reddy PS. Micronuclei assay of exfoliated oral buccal cells: means to assess the nuclear abnormalities in different diseases. J Cancer Res Ther. 2012;8(2):184-91.

12. Torres-Bugarin O, Zavala-Cerna MG, Nava A, Flores-Garcia A, Ramos-Ibarra ML. Potential uses, limitations, and basic procedures of micronuclei and nuclear abnormalities in buccal cells. Dis Markers. 2014;2014:956835. doi: 10.1155/2014/956835.

13. Shashikala R, Indira AP, Manjunath GS, Rao KA, Akshatha BK. Role of micronucleus in oral exfoliative cytology. J Pharm Bioallied Sci. 2015;7(Suppl 2):S409-13.

14. Jones KB, Klein OD. Oral epithelial stem cells in tissue maintenance and disease: the first steps in a long journey. Int J Oral Sci. 2013;5(3):121-9.

15. Klaric E, Par M, Profeta I, Kopjar N, Rozgaj R, Kasuba V, et al. Genotoxic effect of two bleaching agents on oral mucosa. Cancer Genomics Proteomics. 2013;10(5):209-15.

16. Heil J, Reifferscheid G, Waldmann P, Leyhausen G, Geurtsen W. Genotoxicity of dental materials. Mutat Res. 1996;368(3-4):181-94.

17. Galic E, Tadin A, Galic N, Kasuba V, Mladinic M, Rozgaj R, et al. Micronucleus, alkaline, and human 8-oxoguanine glycosylase 1 modified comet assays evaluation of glass-ionomer cements - in vitro. Arh Hig Rada Toksikol. 2014;65(2):179-88.

18. Santos RL, Moura Mde F, Carvalho FG, Guenes GM, Alves PM, Pithon MM. Histological analysis of biocompatibility of ionomer cements with an acid-base reaction. Braz Oral Res. 2014;28(1). doi: 10.1590/S180683242014.50000003.

19. Patel TN, Chakraborty S, Sahoo S, Mehta G, Chavda D, Patel C, et al. Genotoxic potential of aluminum and fluoride on human peripheral blood lymphocytes. Res Environ Life Sci. 2009;2(3):147-52.

20. Wu DQ, Wu Y. Micronucleus and sister chromatid exchange frequency in endemic fluorosis. Fluoride. 1995;28(3):125-7.

21. Rezende EF, Mendes-Costa MC, Fonseca JC, Ribeiro AO. Nuclear anomalies in the buccal cells of children under dental treatment. RSBO. 2011;8(2):182-8.

22. Adad LM, de Andrade HH, Kvitko K, Lehmann M, Cavalcante AA, Dihl RR. Occupational exposure of workers to pesticides: Toxicogenetics and susceptibility gene polymorphisms. Genet Mol Biol. 2015;38(3):308-15.

23. Urcan E, Scherthan H, Styllou M, Haertel U, Hickel R, Reichl FX. Induction of DNA double-strand breaks in primary gingival fibroblasts by exposure to dental resin composites. Biomaterials. 2010;31(8):2010-4.

24. Eramo S, Urbani G, Sfasciotti GL, Brugnoletti O, Bossu M, Polimeni A. Estrogenicity of bisphenol A released from sealants and composites: a review of the literature. Ann Stomatol. 2010;1(3-4):14-21.

25. Chang P, Li B, Yan L, Li R. The biological safety evaluation of new Twinky Star compomer. Chinese J Prosthodont. 2010;4.

26. Quinlan CA, Zisterer DM, Tipton KF, O'Sullivan MI.In vitro cytotoxicity of a composite resin and compomer. Int Endod J. 2002 Jan;35(1):47-55.

27. Nefic H, Handzic I. The effect of age, sex, and lifestyle factors on micronucleus frequency in peripheral blood lymphocytes of the Bosnian population. Mutat Res. 2013;753(1):1-11.

28. Moller P. Genotoxicity of environmental agents assessed by the alkaline comet assay. Basic Clin Pharmacol Toxicol. 2005;96 S1:1-42. 
29. Wojda A, Zietkiewicz E, Witt M. Effects of age and gender on micronucleus and chromosome nondisjunction frequencies in centenarians and younger subjects. Mutagenesis. 2007;22(3):195-200.

30. Bonassi S, Biasotti B, Kirsch-Volders M, Knasmueller S, Zeiger E, Burgaz $\mathrm{S}$, et al. State of the art survey of the buccal micronucleus assay - a first stage in the HUMN(XL) project initiative. Mutagenesis. 2009;24(4):295302 .
31. Bolognesi C, Lando C, Forni A, Landini E, Scarpato R, Migliore L, et al. Chromosomal damage and ageing: effect on micronuclei frequency in peripheral blood lymphocytes. Age Ageing. 1999;28(4):393-7.

Received September 14, 2017 Accepted in revised form September 19, 2019 